7. Reprod. Fertil. (1962) 4, 309-312

\title{
OBSTRUCTION OF THE UROGENITAL TRACT IN SOME RODENTS
}

\author{
J. D. FULTON AND J. A. ARMSTRONG \\ National Institute for Medical Research, Mill Hill, London, N.W.7
}

(Received 14th March 1962)

\begin{abstract}
Summary. In a large percentage of male Schneider mice taken from breeding stock at approximately 1 year of age, the bladder was observed to be grossly distended with urine. The condition was attributable to urethral obstruction by secretory material originating in the vesicular and coagulating glands. The affected animals recovered spontaneously in a period of days, and subsequently proved fertile. Restriction of mating activity while the glands are secreting freely is thought to be the cause of this condition, which did not occur in females and younger males of the same stock nor in other rodents examined.
\end{abstract}

\section{INTRODUCTION}

During routine passage of trypanosome strains, by intraperitoneal inoculation of mice with infected blood with a Pasteur pipette, the latter frequently filled with fluid under pressure when the teat was released. This proved to be urine, coming from a grossly distended bladder which had been accidentally penetrated by the pipette. The animals used were male Schneider mice approximately 1 year old taken from the breeding stock of this Institute a day or two before use. The fur of some with enlarged bladders was moist all over, as if with sweat, and the area around the genitalia was usually stained yellow with leaking urine.

This report summarizes some investigations made into the cause of this abnormality, which was reminiscent of a phenomenon previously encountered in adult male cotton rats that had been infected intraperitoneally with Toxoplasma gondii (Armstrong \& Fulton, 1959).

\section{EXPERIMENTAL}

A total of ninety-eight I-year-old male mice of the Schneider breed, and a similar number of females, was obtained from the original breeding stock, and kept under observation for periods of at least 2 weeks with daily palpation for vesical enlargement. Younger mice of the same breed, only recently introduced into the breeding stock, were examined in the same way; together with several batches of male and female mice of the Parkes and T.O. strains.

Some of the animals that developed enlarged bladders were autopsied, and the pelvic viscera were excised in toto prior to fixation in $10 \%$ neutral formalin. Serial paraffin sections were made through the region of the bladder neck, and 
stained with haematoxylin and eosin to locate and identify the cause of obstruction. Culture of the distended bladder contents was also carried out in a few cases with blood agar slopes. The agglutination titre of the serum of these animals for Toxoplasma antibodies was also determined by the method of Fulton \& Turk (1959).

Since the condition was observed originally in animals removed from a breeding stock, the following additional experiment was performed: fifteen adult male Schneider mice were obtained from the same breeding stock, of which nine had palpably enlarged bladders when received. After 3 weeks the bladders of all but one appeared to be of normal size: ten mice (including seven of those with previously palpable bladders) were then put again with females, and the remaining five were kept in isolation. The effects of these conditions on the size of the bladder, and fertility of the first group, was noted during the next 6 weeks.

\section{RESULTS}

The results of inspection and palpation of the ninety-eight male Schneider mice taken from breeding stock are shown in Table 1 . It will be seen that about

TABLE 1

\begin{tabular}{|c|c|c|c|c|}
\hline \multirow[b]{2}{*}{ No. mice } & \multirow{2}{*}{$\begin{array}{l}\text { Days after } \\
\text { removal from } \\
\text { breeding stock }\end{array}$} & \multicolumn{3}{|c|}{ Size of bladder } \\
\hline & & Very large & Large & Normal \\
\hline 98 & $\begin{array}{r}0 \\
1 \\
3 \\
7 \\
9 \\
14\end{array}$ & $\begin{array}{r}13 \\
15 \\
25 \\
12 \\
3 \\
0\end{array}$ & $\begin{array}{r}38 \\
40 \\
32 \\
21 \\
10 \\
0\end{array}$ & $\begin{array}{l}47 \\
43 \\
41 \\
65 \\
85 \\
98\end{array}$ \\
\hline
\end{tabular}

half of the animals had distended bladders when removed from the breeding stock, and that further enlargement occurred over the next few days. A typically enlarged bladder is shown in Pl. 1, Fig. 1. There was a gradual return to normal size, and the mortality was nil. Enlarged bladders were never detected in the female Schneider mice. The histological examination showed a conspicuous plug of granular eosinophilic material situated in the prostatic segment of the urethra (Pl. 1, Fig. 2). Its size varied in different animals, but it usually reached upwards as far as the vesical opening and in some cases also obstructed the orifices of the ejaculatory ducts. Downwards it extended for a variable distance into the penile segment of the urethra. Its consistence and staining properties were similar to the normal secretory materials seen within the nearby vesicular and coagulating glands. No oedema, or accumulation of inflammatory cells, was revealed in the sections in the vicinity of the urethra, or elsewhere in the pelvic tissues examined. Urine in the enlarged bladders usually contained a whitish sediment, and the blood agar slope cultures invariably revealed the presence of mixed bacterial contaminants. The serum agglutination titres for 
PLATE :

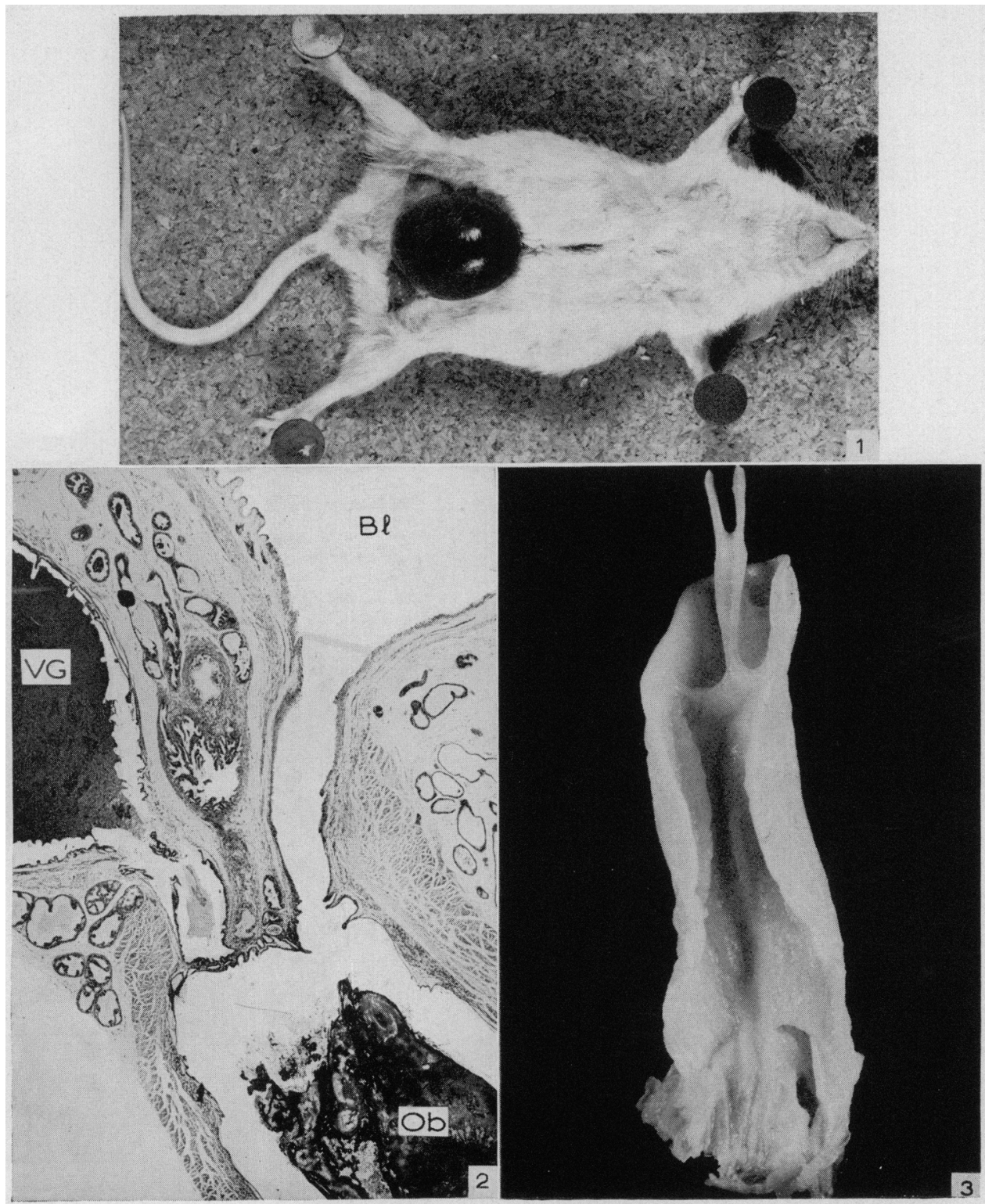

FrG. I. Male Schneider mouse from breeding stock showing grossly distended bladder. $1 \cdot 3$.

FIr. 2. Longitudinal section through the bladder (Bl) and prostatic segment of the urethra, from a mouse with considerable enlargement of the bladder. The dilated urethra is obstructed by a plug of granular material (Ob) similar in appearance to the eosinophilic secretion contained in the nearby vesicular gland (VG). Haematoxylin and eosin. Photomicrograph: $\times 30$

Fig. 3. Epithelial cast of the vagina and lower part of uterine horns from a female cotton rat infected with Toxoplasma gondii. $\times 6$. 
Toxoplasma gondii indicated that this infection was not involved in this series of experiments.

The batch of ten animals that were allowed to mate again showed normal fertility and marked, but irregular, variations occurred in the size of their bladders during the 6-week-period of observation. Sometimes for a period of days the bladder was found to be as large as any of those recorded in Table 1. On the other hand, in the batch of five, kept in isolation during the same period, no apparent variation in size of the bladder occurred.

Young male Schneider mice recently added to the breeding stock did not suffer from bladder distension when taken out; nor did forty-eight fully grown male mice of the Parkes strain and thirty-six similar T.O. mice kept under observation for some weeks. Similarly, hundreds of male and female Parkes mice from non-breeding stock, also hamsters, hooded and white rats and cotton rats, have passed through our hands in recent years, but on no occasion were distended bladders observed.

\section{DISCUSSION}

It appears from the foregoing observations that the gross bladder distension which occurred in a large percentage of the male Schneider mice removed from breeding stock was due to urethral blockage. It was evidently caused by coagulation within the urethra of secretory products, mainly from the vesicular and coagulating glands. The resulting plug, incorporating a variable number of spermatozoa, formed a mechanical obstruction to the flow of urine. Most of the animals survived, evidently because the obstruction was not complete. The experiments summarized in Table 1 showed that the condition was temporarily accentuated by withdrawal of the older male mice from the breeding stock. The condition may thus have been precipitated by disturbance of their longestablished mating habits. Occurrence of the phenomenon in the breeding stock itself has not been explained by these experiments. It is conceivable that the glands concerned became excessively active in older animals with resulting coagulation of the secretory products in the urethra, possibly precipitated by some irregularity of mating activity. The particular susceptibility of Schneider mice is puzzling, and remains unexplained.

A comparable state of bladder distension due to urethral obstruction has been described in male cotton rats, within 3 days of intraperitoneal inoculation of Toxoplasma gondii (Armstrong \& Fulton, 1959). It did not occur in uninfected cotton rats, nor was it in that case associated with the breeding stock. The inspissated secretion was in such amount as to become visible at the penile tip and the condition was explained as a reaction to the inflamed and congested state of infected pelvic tissues. As in the present study, bladder enlargement was not seen in females. However, in female cotton rats infected by the peritoneal route with Toxoplasma gondii excessive keratinization occurs in the vaginal epithelium. This recently came to our notice following extrusion of a complete cast of the vagina and lower uterine horns (Pl. 1, Fig. 3); histological examination showed this to be composed of sloughed epithelium, and so to be quite different from the glandular secretory products found in the males although possibly of similar aetiology. 
Spontaneous urethral obstruction of the kind now reported, has not to our knowledge been described previously. Although the condition does not prove lethal, it appears to be quite common and is obviously distressing for the animals; it could also limit the usefulness of otherwise healthy stock in biological work.

\section{ACKNOWLEDGMENTS}

It is a pleasure to acknowledge the help of Mr L. A. Hills with the animals.

\section{REFERENGES}

Armstrong, J. A. \& Fulton, J. D. (1959) Observations on the pathology of Toxoplasmosis in the cotton rat. Brit. F. exp. Path. 40, 225.

Fulton, J. D. \& TURK, J. L. (1959) A direct agglutination test for Toxoplasma gondii. Preliminary communication. Lancel, ii, 1068. 